Joice de Souza Santos

As embaixadas dos reinos da costa africana como mediadoras culturais:

Missões diplomáticas em Salvador, Rio de Janeiro e Lisboa (1750-1823)

Dissertação de Mestrado

Dissertação apresentada como requisito parcial para obtenção do grau de Mestre pelo programa de Pós-Graduação em História Social da Cultura do Departamento de História da PUC-Rio

Orientadora: Prof ${ }^{\underline{a}}$ Ivana Stolze Lima

Rio de Janeiro Setembro de 2012 
Joice de Souza Santos

\section{As embaixadas dos reinos da costa africana como mediadoras culturais: \\ Missões diplomáticas em Salvador, Rio de Janeiro e Lisboa (1750-1823)}

Dissertação apresentada como requisito parcial para obtenção do grau de Mestre pelo Programa de PósGraduação em História Social da Cultura do Departamento de História do Centro de Ciências Sociais da PUC-Rio. Aprovada pela Comissão Examinadora abaixo assinada.

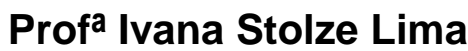

Orientadora

Departamento de História - PUC-Rio

Prof. Ilmar Rohloff de Mattos Departamento de História - PUC-Rio

Prof. Alexandre Vieira Ribeiro

Departamento de História - UFF

Prof ${ }^{\text {a }}$ Mônica Herz

Vice-Decana de Pós-Graduação do Centro de Ciências Sociais

PUC-Rio

Rio de Janeiro, 18 de setembro de 2012. 
Todos os direitos reservados. É proibida reprodução total ou parcial do trabalho sem a autorização do autor, do orientador e da universidade.

\section{Joice de Souza Santos}

Graduou-se em História pela PUC-Rio (Pontifícia Universidade Católica do Rio de Janeiro) em 2009. Atuou como pesquisadora em projetos editoriais sobre história e cultura brasileira. Atualmente é editora iconográfica na Revista de História da Biblioteca Nacional.

Ficha Catalográfica

Santos, Joice de Souza

As embaixadas dos reinos da costa africana como mediadoras culturais: missões diplomáticas em Salvador, Rio de Janeiro e Lisboa (1750-1823) / Joice de Souza Santos ; orientadora: Ivana Stolze Lima. - 2012.

182 f. : il. (color.) ; $30 \mathrm{~cm}$

Dissertação (mestrado)-Pontifícia Universidade Católica do Rio de Janeiro, Departamento de História, 2012.

Inclui bibliografia

1. História - Teses. 2. História social da cultura. 3. História da África. 4. História do mundo atlântico. 5. História da América portuguesa. 6. Relações diplomáticas. 7. Tráfico de escravos. I. Lima, Ivana Stolze. II. Pontifícia Universidade Católica do Rio de Janeiro. Departamento de História. III. Título.

CDD: 900 
Ao "meu pé de laranja lima":

D. Vânia, minha mãe.

Ao Pedro pelas risadas e

à D. Maria (in memoriam),

por ter sonhado junto comigo 


\section{Agradecimentos}

Agradeço, em primeiro lugar, a Deus por ter me sustentado não só durante o período de pesquisa e escrita deste trabalho, mas por todos os dias da minha vida. Muito obrigada por me amar tanto, Pai.

À CAPES e à PUC-Rio, agradeço a bolsa de pesquisa fornecida. Os resultados dessa pesquisa não seriam os mesmos sem o auxílio para importação de livros, reprodução de documentos e demais atividades acadêmicas.

À minha orientadora, Ivana Stolze Lima, agradeço a paciência e imensa generosidade com a minha pesquisa. Manhãs e tardes foram disponibilizadas para discussão de textos e de capítulos apresentados, indicando pontos a serem trabalhados, sugerindo leituras e emprestando livros. Quando os encontros presenciais não foram possíveis, idéias e textos foram trocados via e-mail, sempre visando o melhor aproveitamento do trabalho. Não tenho palavras para agradecer a sua orientação e carinho, que pude perceber quando dividi as angústias da pesquisa e da escrita.

Ao professor Ilmar Rohloff de Mattos, agradeço por inicialmente ter assumido a minha orientação, pelas sugestões e pelo carinho dispensado a mim desde a graduação. Obrigada por despertar em mim a vontade de ser pesquisadora e por me ensinar a amar a licenciatura.

Ao professor Alexandre Ribeiro, por ter participado da minha defesa de projeto, e pelas considerações e sugestões feitas, que contribuíram sobremaneira para o resultado deste trabalho.

Aos funcionários do Departamento de História: Anair, minha mãe Cleuza, Cláudio, Edna e Moisés agradeço o carinho e as conversas que tivemos ao longo desses oito anos entre graduação e pós-graduação. Conviver com vocês nesses longos anos fizeram de mim uma pessoa mais feliz e divertida.

Ao embaixador Alberto da Costa e Silva, agradeço a generosidade por abrir a sua biblioteca particular para que eu pudesse pesquisar alguns livros, e por me fornecer outras indicações de leitura.

Agradeço aos amigos da Puc-Rio, que fiz ao longo da graduação, e que seguiram comigo na Pós, onde dividimos angústias, discussões e muitas risadas: Anderson Ignácio, Carlos Taveira, Cristiane Furtado, Eduardo Gonçalves e Mario Miranda, vocês foram incríveis nesses últimos anos. 
Aos amigos da Revista de História da Biblioteca Nacional, agradeço as indicações de livros, os comentários de textos, a paciência com as minhas crises acadêmicas e, principalmente, por todo amor e carinho. Agradeço a minha amada equipe: Amanda Alvarenga, Agnes Alencar, Felipe Rodrigues, Nataraj Trinta, Nathalia Fernandes, Patrícia Krepp, Roberta Souza e Úrsula Polverini. Não poderia esquecer de Carolina Ferro, Carolina Rocha e de grandes amigos que conheci e reencontrei na redação: Fabio Pedrosa, pelos conselhos e preocupação; Bruno Garcia, pelo carinho e incentivo e Cristiane Nascimento, cuja amizade me fez crescer como profissional e pessoa, obrigada por tudo.

Àqueles que fora do círculo acadêmico ou de trabalho fazem a minha vida mais alegre e confortante: Clarisse Barroso, com o melhor abraço que um amigo pode dar; Daniel Wyatt, pelo sorriso mais contagiante; Vanessa Nascimento, pelo carinho inenarrável; Jordana Lima, pelas boas risadas e orações; Fê de Souza, pelo amor e carinho de irmã; Paulinho Motta, o irmão que foi um presente; Paloma Brito, por sua sinceridade e amor; Samantha Parente, pela animação e carinho; Baltasar Ruiz, por todo carinho e respeito; Leonardo Távora, pelo carinho e infinitas orações; à minha irmã Isabel Alencar, por chorar e rir comigo em momentos que só Deus sabe.

Não poderia jamais esquecer de agradecer aos meus familiares que tanto me incentivaram nesse processo. Aos meus tios(as) e primo(as), o meu muito obrigada. Quero também deixar registrado o meu carinho por Francisco e Alessandra Araújo, Ricardo e Milena Hudson.

Ao meu amado irmão Pedro, por me fazer rir e por me fazer chorar, porque você tornou a nossa casa muito mais alegre e imprevisível. À minha mãe, amada minha, aquela que é presente de Deus na minha vida. Muito obrigada pelo carinho, incentivo, por segurar na minha mão em momentos que eu estava cabisbaixa, por me levantar para ficar lado a lado contigo. À minha querida e amada tia Maria, in memoriam, agradeço por ter sonhado comigo, por todas as palavras de incentivo e de amor.

Mais uma vez agradeço a todos aqui mencionados, por terem me acompanhado durante a concretização desse sonho, um pedacinho de vocês está nessas páginas. 


\section{Resumo}

Santos, Joice de Souza; Lima, Ivana Stolze. As embaixadas dos reinos da costa africana como mediadoras culturais: missões diplomáticas em Salvador, Rio de Janeiro e Lisboa (1750-1823). Rio de Janeiro, 2012. 182 p. Dissertação de Mestrado - Departamento de História, Pontifícia Universidade Católica do Rio de Janeiro.

A presente dissertação de mestrado tem por objetivo analisar as embaixadas dos reinos de Daomé, Ardra e Onim que estiveram presentes em Salvador, no Rio de Janeiro e em Lisboa entre 1750 e 1823. Para tal, a pesquisa se utilizou das correspondências trocadas entre os reinos da costa africana e o governo português estabelecido em Salvador e em Lisboa, além de utilizar relatos de viajantes que foram para estes reinos. Esta pesquisa, cujo enfoque está nas relações do reino daomeano com Portugal permite compreender os diálogos culturais estabelecidos entre as partes. As relações entre as duas margens do Atlântico iam além do tráfico de escravos e a análise da documentação abre possibilidades para discutir alguns aspectos bem como problematizar os mediadores de tais missões diplomáticas.

\section{Palavras-Chave}

História da África; História do Mundo Atlântico; História da América Portuguesa; Relações diplomáticas; Tráfico de Escravos 


\section{Abstract}

Santos, Joice de Souza; Lima, Ivana Stolze (advisor). The african coast embassies as cultural mediators: diplomatic missions in Salvador, Rio de Janeiro and Lisbon. Rio de Janeiro, 2012. 182 p. MSc Dissertation Departamento de História, Pontifícia Universidade Católica do Rio de Janeiro.

This dissertation seeks to analyse the kingdom's Embassies of Daome, Ardra and Onim, which have been in Salvador, Rio de Janeiro and Lisbon between 1750 and 1823. According to that, this research focuses on the letters exchanged between these coastal African kingdoms and the Portuguese government established in Salvador and Lisbon. The reports made by travelers who visited these places are also analysed. This study also examine the relationship between Portugal and the kingdom of Daome. In order to understand the cultural dialogues as the result of this relations. The relationships between the two sides of the Atlantic Ocean contains more complexity than just slave trade and the documents enable us to discuss other aspects of these diplomatic missions.

\section{Keywords}

African History; Atlantic World History; Portuguese America History; Diplomatic relations; Slave trade 


\section{Sumário}

1. Introdução

2. "Pela Manutenção da nossa amizade". Os reinos do Daomé, Ardra e Onim e sua relação co Portugal 24

2.1. Breve histórico das embaixadas 26

2.2. Embaixadas dos Reinos do Daomé, Ardra e Onim 45

2.3. Limites da amizade 56

3. "Para causar admiração". A presença de elementos culturais nas embaixadas $\quad 58$

3.1. Os poderes religioso e político expressos nas correspondências 61

3.2. Trânsitos culturais 81

4. "Envio um branco meu". Mediadores culturais das embaixadas dos reinos da costa africana 92

4.1. A cultura escrita em Portugal e na costa africana 95

4.2. Intérpretes como mediadores culturais 104

4.2.1. Intérpretes da língua falada 109

4.2.2. Intérpretes da língua escrita 112

4.3. Últimas considerações 124

5. Conclusão 128

6. Referências bibliográficas 132

$\begin{array}{ll}\text { 7. Anexos } & 150\end{array}$ 


\section{Lista de figuras}

Figura 1 - Retrato do embaixador do Congo, óleo sobre tela de Jasper Benkx. 1643.

Figura 2 - Servo com caixa de ouro, óleo sobre tela de Jasper Bankx. 1643.

Figura 3 - Servo com presa, óleo sobre tela de Jasper Bankx. $1643 . \quad 32$

Figura 4 - Mapa manuscrito feito pelo padre Vicente Ferreira Pires quando ocorreu a sua viagem missionária de conversão do reino Daomé em fins do XIX.

Figura 5 - "The plataform of the Ah-toh"

Figura 6 - "The human sacrifices of the Ek-que-nooah-toh"

Figura 7 - Detalhe da última página da carta enviado pelo rei do Daomé ao Príncipe D. João em 1805.

Figura 8 - Detalhes da última página da carta enviada pelo rei de Ardra ao rei D. João em 1810

Esquema 1 - Esquema de comunicação entre os reinos de Portugal e do Daomé, enfatizando a importância dos intérpretes 